\title{
Lightweight geopolymer composites as structural elements with improved insulation capacity
}

\author{
Glikeria Kakali, Dimitris Kioupis, Aggeliki Skaropoulou and Sotiris Tsivilis \\ National Technical University of Athens, School of Chemical Engineering, Athens, Greece
}

\begin{abstract}
This study concerns the development of lightweight fly ash based geopolymers which can be applied as alternatives to the traditional lightweight concrete. Different kinds of expanded polystyrene were used as lightweight agents. The results showed that lightweight geopolymers were successfully prepared, exhibiting compressive strength and density in the range $7.70-29.57 \mathrm{MPa}$ and $0.97-1.57 \mathrm{~g} / \mathrm{cm}^{3}$, respectively. The product containing $3 \% \mathrm{w} / \mathrm{w}$ of commercial expanded polystyrene possesses low thermal conductivity $(0.16$ $\mathrm{W} / \mathrm{mK}$ ) combined with sufficient mechanical strengths (11 MPa), excellent stability and fire resistance while its water absorption is comparable to that of conventional construction materials (cement mortars, concrete).
\end{abstract}

\section{Introduction}

Lightweight building elements generally exhibit improved thermal insulation and relatively good strength. The main benefits by the application of these elements are associated with the reduction of the total load of the structure making savings in foundations and reinforcement as well as the improved thermal properties. Such elements usually consist of a cementitious binder and a lightweight aggregate (polystyrene beads, expanded perlite etc.). Traditionally, the cementitious material is OPC. Geopolymers or alkali activated materials are produced via the alkali activation of aluminosilicate materials and can be considered as alternatives to OPC [1-3]. The main advantages of geopolymers are the use of wastes and by-products as raw materials as well as the very low embodied energy and $\mathrm{CO}_{2}$ footprint compared to the conventional cementitious materials $[4,5]$.

This study concerns the development of lightweight geopolymer composites with enhanced insulation capacity and sufficient mechanical strength, for application as structural elements in energy efficient buildings. For the geopolymers production, a type F fly ash (Megalopolis, Greece) was used as the main aluminosilicate source. In order to reduce the density of the products, different types of polystyrene particles with varying shapes and sizes were tested at a content ranging between $0.5-3.0 \% \mathrm{w} / \mathrm{w}$ (fly ash based). In all cases, compressive and bending strength, apparent density and thermal conductivity were measured. In order to examine the durability of the products, moisture absorption and sorptivity measurements were conducted while the fire resistance was evaluated through flammability tests.

\section{Experimental}

The fly ash used in this study comes from the power station of Megalopolis in Greece. This material can be classified as Type $\mathrm{F}$ according to ASTM C 618, as the sum of the oxides $\mathrm{SiO}_{2}+\mathrm{Al}_{2} \mathrm{O}_{3}+\mathrm{Fe}_{2} \mathrm{O}_{3}$ is higher than $70 \%$. Fly ash was previously ground at a mean particle size $\left(\mathrm{d}_{50}\right)$ approximately $20 \mu \mathrm{m}$. This is the typical fineness of fly ash when used as main constituent in blended cements. The chemical composition of fly ash is presented in Table 1.

Table 1. Chemical composition of fly ash (\% w/w).

\begin{tabular}{llllllll}
\hline $\mathrm{SiO}_{2}$ & $\mathrm{Al}_{2} \mathrm{O}_{3}$ & $\mathrm{Fe}_{2} \mathrm{O}_{3}$ & $\mathrm{CaO}$ & $\mathrm{MgO}$ & $\mathrm{K}_{2} \mathrm{O}$ & $\mathrm{Na}_{2} \mathrm{O}$ & $\mathrm{SO}_{3}$ \\
\hline 45.52 & 22.13 & 8.99 & 14.75 & 2.84 & 1.55 & 0.72 & 1.69 \\
\hline
\end{tabular}

The synthesis of the lightweight geopolymers includes three steps: a) the preparation of the activation solution, b) the mixing of the raw materials (fly ash and lightweight agents) with the activation solution and c) the molding and the curing of the specimens. The activation solution contains soluble $\mathrm{Si}$ in form of sodium silicate (3.34 $\mathrm{SiO}_{2} \cdot \mathrm{Na}_{2} \mathrm{O}$, Multiplass Greece) and $\mathrm{NaOH}(\geq 98.0 \%$, CAS No. 1310-73-2) in order to provide the alkaline environment that is necessary for the activation of the geopolymerization reactions. The activation solutions were stored for a minimum of $24 \mathrm{~h}$ prior to use, to allow equilibrium. In all mixtures, the silicon to aluminum $(\mathrm{Si} / \mathrm{Al})$ and the sodium to aluminum $(\mathrm{Na} / \mathrm{Al})$ molar ratios as well as the solids to liquids (s/l) mass ratio were kept constant to 2.4, 0.85 and 2.8, respectively [6].

In order to prepare lightweight geopolymers, the incorporation of lightweight additives such as expanded polystyrene (EPS), was investigated. Six different types 
of expanded EPS were tested. In particular, we used 3 types of commercial EPS and 3 types developed by Fraunhofer ICT institute. The extent of EPS incorporation ranged between $0.5-3.0 \% \mathrm{w} / \mathrm{w}$ on fly ash basis. Table 2 shows the EPS types along with their characteristics. The lightweight agents were effectively mixed with the fly ash in order to obtain a homogenous blend. Then, this blend and the activation solution were mechanically mixed (standard mortar mixer: Controls 65-L0005) to form an homogenous slurry which was poured to 50x50x50 mm cubic molds and mildly vibrated. The specimens were left at room temperature for $2 \mathrm{~h}$ and then were transferred to an oven at $70^{\circ} \mathrm{C}$ for $24 \mathrm{~h}$ [6]. Compression and bending tests were carried out on a Toni-technik uniaxial testing press, 7 days after the specimens' preparation (load rate $1.5 \mathrm{kN} / \mathrm{s}$, according to the EN196-1 requirements). For each sample three specimens were prepared and tested.

Table 2. EPS types applied in this study.

\begin{tabular}{lcc}
\hline EPS code & EPS type & $\begin{array}{c}\text { Incorporation } \\
\text { range (\%) }\end{array}$ \\
\hline Com1 & Commercial - recycled & $0.5-3.0$ \\
Com2 & Commercial - Sphere 1-3mm & $0.5-3.0$ \\
Com3 & Commercial - Sphere 3-5mm & $0.5-3.0$ \\
FH1 & 1\% polywex / 6\% pentane & $1.0-2.0$ \\
FH2 & 1\% grapheme / 6\% pentane & $1.0-2.0$ \\
FH3 & Coperion & $1.0-2.0$ \\
\hline
\end{tabular}

Geopolymer specimens were submitted to moisture absorption tests at laboratory conditions and in water. In the first case, the examined specimens are exposed to environmental conditions and the mass changes are recorded versus time. The absorption tests in water involve the immersion of the samples into tap water and the record of the mass till variations not greater than 0.2 $\%$ are observed.

Sorptivity tests measure the rate of water absorption by capillary suction of the specimens placed in contact with the water [7]. In such tests, the low part of specimens' sides is covered with adhesive tape. Then, the specimens are submerged into water in a $5 \mathrm{~mm}$ depth and the mass increase is recorded after 5, 10, 20, 40, 60, 90 Kal $120 \mathrm{~min}$. In order to export the sorptivity values of the samples, diagrams of water absorption per unit area $\left(\mathrm{g} / \mathrm{mm}^{2}\right)$ vs square root of time $\left(\mathrm{t}^{0.5}\right)$ were plotted. The slop of the curves indicates the sorptivity magnitude.

The thermal conductivity of the samples was determined by means of the Heat Flow method, on a Netzsch HFM 436 lamda Heat Flow Meter, which meets the EN12667 and ASTM C518 requirements. The samples were left at standard laboratory conditions before testing. The mean temperature was set at $10^{\circ}$, with 10 degrees temperature difference.

For the evaluation of the flame behavior of the lightweight geopolymers, JAR-25 standard (\$25.853 (a) and Appendix F, Part I, para (a) (1) (ii), AITM 2.0002 B) was applied. For conducting these tests, three prismatic specimens $(30.5 \times 9.5 \times 3 \mathrm{~cm})$ for each sample were prepared.

\section{Results and discussion}

\subsection{Mechanical properties}

Figure 1 presents the effect of common expanded polystyrene (Com2) on the compressive strength and the density of the produced geopolymers. As it was expected, the incorporation of expanded polystyrene in the geopolymeric matrix favours the production of lightweight materials However, this reduction is accompanied with a more intense decrease of compressive strength values. The addition of $3 \% \mathrm{w} / \mathrm{w}$ of Com 2 decreases the density by $40 \%$, with the reduction of strength being much higher $(80 \%)$. Despite the low content of expanded polystyrene, its volume fraction in the geopolymer is high and the dilution of binding matrix causes a severe decrease of compressive strength. Similar behavior is observed for the whole EPS series. Depending on the kind and percentage of polystyrene, lightweight geopolymers with compressive strength in the range $7.70-29.57 \mathrm{MPa}$ and apparent density in the range $0.97-1.57 \mathrm{~g} / \mathrm{cm}^{3}$ were developed. The reference geopolymer (0\% w/w EPS) exhibits $56 \mathrm{MPa}$ and 1.77 $\mathrm{g} / \mathrm{cm}^{3}$ of compressive strength and density, respectively.

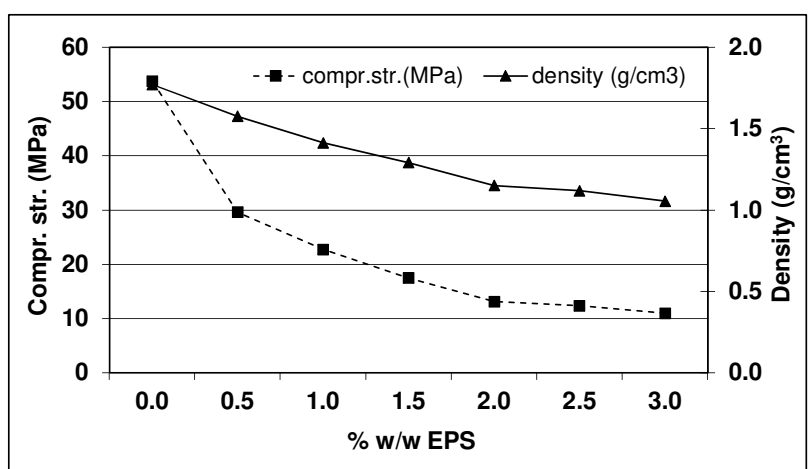

Fig. 1. Compressive strength and density of geopolymers with Com 2 expanded polystyrene.

Figure 2 shows the compressive strength and the density of the geopolymers prepared with the highest incorporation level of the different EPS types. In all cases, the compressive strength of the geopolymers is around $10 \mathrm{MPa}$ showing that the specimens keep a sufficient mechanical strength. The density of the corresponding geopolymers varies from 0.97 to 1.33 $\mathrm{g} / \mathrm{cm}^{3}$. The density of the sample prepared by FH2 EPS is too high for the development of a structural element with enhanced thermal behavior. The lowest density was found in geopolymer with FH1 (1\% polywex and 6\% pentane). However, the $3 \% \mathrm{w} / \mathrm{w}$ Com 2 geopolymer keeps the best combination of properties for the development of a lightweight structural element $(\mathrm{C}=11 \mathrm{MPa}$ and $\mathrm{d}=$ $\left.1.05 \mathrm{~g} / \mathrm{cm}^{3}\right)$ and therefore it was promoted for further investigation. 


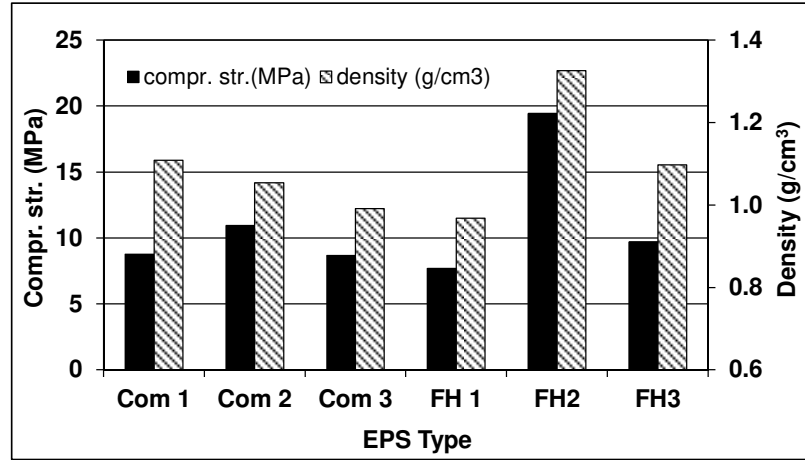

Fig. 2. Compressive strength and density of geopolymers prepared with different types of expanded polystyrene.

The flexural strength of the reference and the $3 \%$ w/w Com2 geopolymers was measured 6.03 and 2.15 $\mathrm{MPa}$, respectively.

\subsection{Durability tests}

Figure 3 presents the mass variations of the reference and the lightweight $(3 \% \mathrm{w} / \mathrm{w}$ Com 2$)$ geopolymer when exposed to environmental conditions for a period of 370 days. The results showed that both materials exhibit near zero mass variations. In addition, a stabilization of the mass values of the two materials was observed after approximately 150 days. In particular, the reference and the $3 \%$ w/w Com 2 geopolymer exhibit $\pm 1.05 \%$ and $\pm 0.69 \%$ mass variations after 370 days of exposure, respectively. The EPS geopolymer presents a greater mass stability in relation to the reference geopolymer. This can be explained in the basis of the tendency of the geopolymer matrix to absorb water. In the case of the EPS product the geopolymer matrix is highly diluted by EPS and so the water absorption is considerably lower.

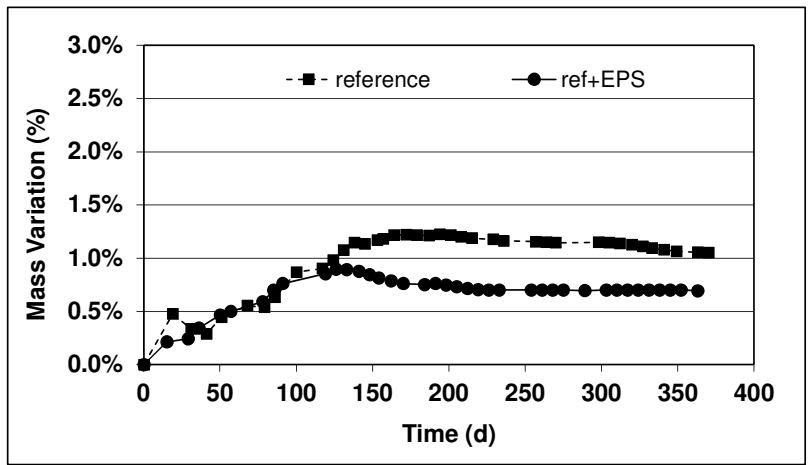

Fig. 3. Mass variations of a reference and a 3\% w/w EPS geopolymer when exposed to environmental conditions.

The water immersion tests showed that the lightweight geopolymer exhibits a water absorption of $11.8 \%$. This water absorption value is comparable to conventional building materials. For example, cement mortars present water absorption 5-12\%, depending on their compressive strength. Figure 4 presents photos of $3 \%$ w/w Com 2 specimens which were immersed in water for 270 days. The specimens remained unaffected by water, maintaining their cubic shape with no cracks or surface damages even after 270 days of immersion.

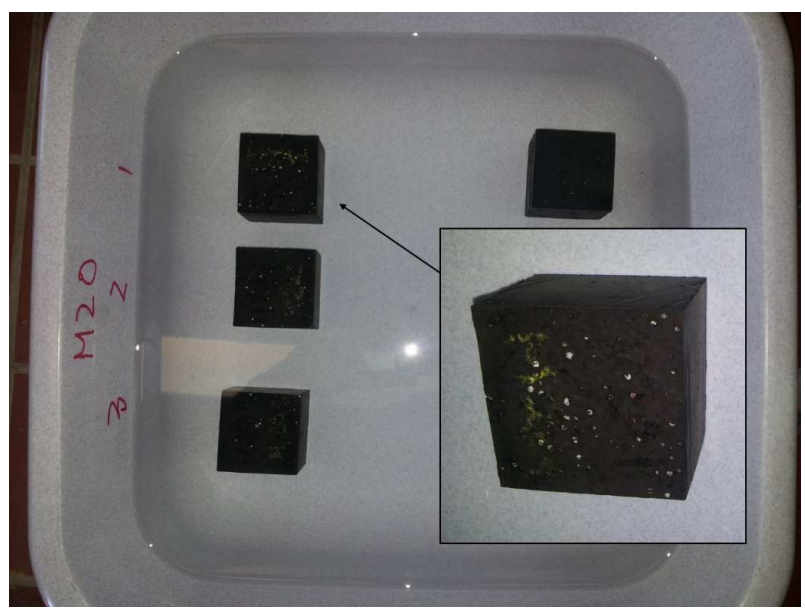

Fig. 4. Photos of $3 \%$ w/w Com 2 specimens after immersion into water for 270 days.

Figure 5 presents the curves of $\%$ water absorption vs. time for the reference and lightweight samples as they were exported from sorptivity tests. As it is seen in figure 5 , the lightweight geopolymer ( $3 \% \mathrm{w} / \mathrm{w}$ Com 2$)$ exhibited significant lower water absorption values in comparison to the reference geopolymer. This fact can be explained in terms of EPS nature. It seems that geopolymeric matrix has a higher ability to absorb water than EPS the volume fraction is high $(\sim 80 \%)$, resulting to significantly reduced water absorption.

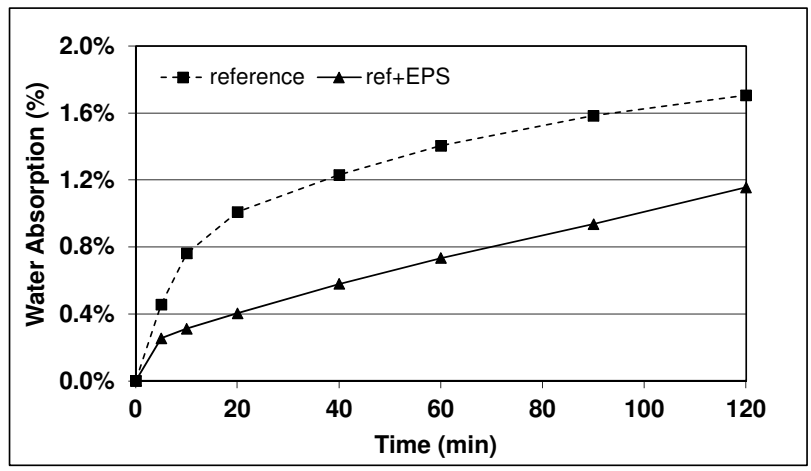

Fig. 5. Water absorption (\%) vs. time (min) for the reference and $3 \% \mathrm{w} / \mathrm{w}$ Com 2 specimens.

In order to export the sorptivity values of the samples, the curve of water absorption per unit area $\left(\mathrm{g} / \mathrm{mm}^{2}\right)$ vs square root of time $\left(\mathrm{t}^{0.5}\right)$ were plotted. The slop of the curve indicates the sorptivity magnitude. An indicative sorptivity diagram is showed in Figure 6 for a 3\% w/w Com 2 specimen. In order to measure the sorptivity of the reference and 3\% w/w Com2 geopolymers, three specimens of each synthesis were prepared and tested.

The mean sorptivity value of $3 \% \mathrm{w} / \mathrm{w}$ EPS specimens was calculated at $0.051 \mathrm{~mm} / \mathrm{min}^{0.5}$ while that of the reference specimens was three times larger $(0.150$ $\left.\mathrm{mm} / \mathrm{min}^{0.5}\right)$. These values are comparable or even lower to the typical sorptivity values of concrete $(0.09-0.17$ $\mathrm{mm} / \mathrm{min}^{0.5}$ ) [7]. 


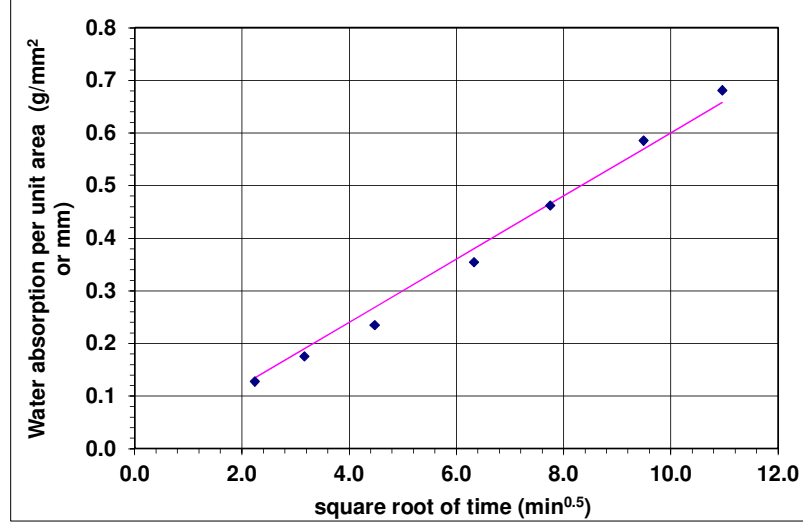

Fig. 6. Water absorption per unit area vs square root of time for the specimen with COM2 $(3 \% \mathrm{w} / \mathrm{w})$

\subsection{Thermal conductivity}

Figure 7 shows the density and thermal conductivity of the reference geopolymer and the geopolymer with EPS $(3 \% \mathrm{w} / \mathrm{w})$. It is observed that the values of both thermal conductivity and density, drastically, decrease with the incorporation of the expanded polystyrene. Considering the high volume fraction of EPS in the matrix, the geopolymer volume that can accumulate heat is reduced and so does the conductivity. In particular, the thermal conductivity values of the reference material $(0 \% \mathrm{w} / \mathrm{w}$ EPS) and the lightweight geopolymer (3\% w/w Com 2$)$ were 0.30 and $0.16 \mathrm{~W} / \mathrm{mK}$, respectively.

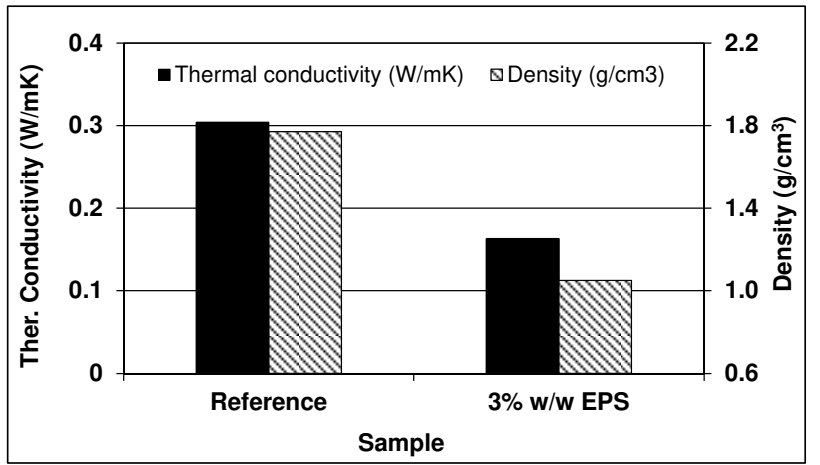

Fig. 7. Thermal conductivity and density of reference and lightweight geopolymers.

\subsection{Fire resistance}

Figure 8 presents the configuration of the flammability test along with a photo of the burned sample. All geopolymer samples did pass the JAR-25 test. From photo $b$, it is obvious that even if the flammable EPS was burnt out, the geopolymer matrix prevents any spread of fire. There was no spread of the flame to the rest of the sample.

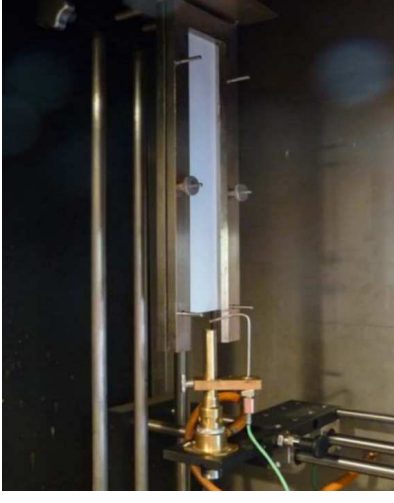

a

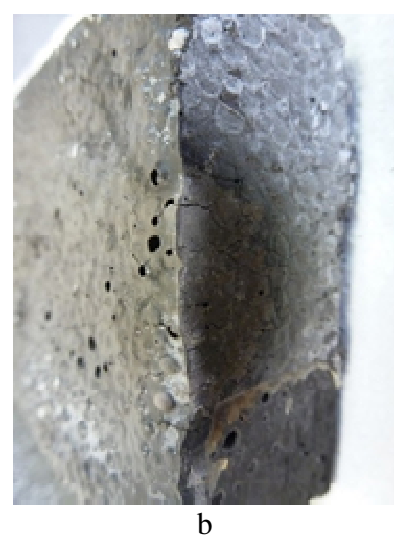

Fig. 8. Configuration of JAR-25 test (a) and burned sample (b)

\section{Conclusions}

In this study, different types of expanded polystyrene were applied in the production of lightweight geopolymer composites from fly ash. Depending on the kind and percentage of polystyrene, lightweight geopolymers with compressive strength in the range $7.70-29.57 \mathrm{MPa}$ and apparent density in the range $0.97-1.57 \mathrm{~g} / \mathrm{cm}^{3}$ were developed. The product containing $3 \% \mathrm{w} / \mathrm{w}$ commercial expanded polystyrene can be considered for the development of structural elements with enhanced thermal behaviour since it exhibits low thermal conductivity value $(0.16 \mathrm{~W} / \mathrm{mK})$ combined with sufficient mechanical strengths (11 MPa). Furthermore, this product possesses excellent stability and fire resistance, while its water absorption is comparable to that of the conventional construction materials (cement mortars, concrete).

\section{Acknowledgments}

This research work has been financed by the European Union Seventh Framework Program (FP7-2013NMPENV-EeB, "Multifunctional facades of reduced thickness for fast and cost-effective retrofitting, MFRetrofit", Grant No.: 609345).

\section{References}

1. J. Davidovits, J. Ther. Anal. 37, 1633 (1991)

2. J.L. Provis, J.S.J. van Deventer, Alkali-activated materials: State-of-the-Art Report (Springer/RILEM, 2013)

3. P. Duxson, J.L. Provis, J. Amer. Ceram. Soc. 91, 3846 (2008)

4. J.L. Provis, S.A. Bernal, Ann. Rev. Mater. Res. 299 (2014)

5. P. Duxson, A. Fernández-Jiménez, J.L. Provis, G.C. Lukey, A. Palomo, J.S.J. Van Deventer, J. Mater. Sci. 42, 2917 (2007)

6. C. Panagiotopoulou, S. Tsivilis, G. Kakali, Constr. Build. Mater. 91, 17 (2015)

7. A.M. Neville, Properties of concrete, (Addison Wesley Longman Limited, England, 1996) 